\title{
Relato das vivências de Estágios curriculares: (des)encantamentos e desafios
}

Laura Leal Moreira

Denise Nascimento Silveira

\section{Resumo}

O presente relato é o resultado das reflexões sobre os estágios curriculares supervisionados realizados durante a graduação em Licenciatura em Matemática pela Universidade Federal de Pelotas (UFPel). Os estágios são etapas obrigatórias em um curso de licenciatura e tem como objetivo aproximar o futuro professor da realidade do seu campo de vivências de práticas propostas na universidade e de aprendizagens com os professores titulares das turmas, que recebem esses estagiários. Considerando que ao conviver com a prática na prática de uma instituição de ensino o acadêmico poderá avaliar o seu processo formativo e tomar decisões que são possíveis somente quando estamos no campo de trabalho. Essa vivência de prática é avaliada pelo acadêmico, pelo professor que recebe esse estagiário e também através de um relatório reflexivo, com todos registros das experiências desse período de prática e das relações dessas práticas com os conhecimentos construídos na universidade. Dessa forma o futuro professor pode definir a continuidade na profissão ou um outro redimensionamento profissional como a busca da pós-graduação, ou a busca de espaços como pesquisador. Nessa perspectiva o estágio e um momento fundamental na vida dos acadêmicos pois permite a organização e delineamento profissional desses acadêmicos. 


\section{Introdução}

Este texto é parte do relatório obrigatório entregue ao final da disciplina de Estágio II, da primeira autora, que teve como professora orientadora a segunda autora, durante a disciplina de Estágio II do curso de Licenciatura em Matemática. O estágio ocorreu no ano de 2015, em uma turma de $1^{\text {a }}$ Ano do Ensino Médio Politécnico, do Instituto Estadual de Educação Assis Brasil (IEEAB), na cidade de Pelotas-RS. Esse relato pretende apresentar os (des)encantamentos e desafios de uma licencianda frente a regência de uma turma de estudantes do noturno de uma escola pública. Vale salientar que a escrita desse relato, de uma experiência ocorrida no ano de 2015, sofreu algumas alterações em relação ao texto original, pois questões que foram expressas naquele momento, hoje mudaram e alguns pensamentos não seguem mais os mesmos. Como autora, passei por um amadurecimento intelectual na vivência de meu mestrado.

Traduzo essa minha condição com o pensamento de Magda Soares, do livro Metamemória-memórias: travessia de uma educadora:

Exatamente assim é que me sinto: com as mãos atadas pelo que hoje sou, condicionada pelo meu presente, é que procuro narrar um passado que refaço, re-construo, re-penso com as imagens e ideias de hoje. A própria seleção daquilo que incluo na narração obedece a critérios do presente: escolho aquilo que tenha relações com o sistema de referências que me dirige, hoje. A (re)construção de meu passado é seletiva: faço-a a partir do presente, pois é este que me aponta o que é importante e o que não é; não descrevo, pois; interpreto (SOARES, 2001, p. 40).

Dessa forma, apresento um texto com a interpretação da minha experiência, da minha vivência como professora de matemática de uma turma de ensino médio de uma escola da rede pública de Pelotas-RS.

\section{O cenário}

Na realização do Estágio I, apesar de todos os imprevistos ${ }^{1}$, foi nesse momento que conheci a realidade de uma escola. Porém, no estágio II me encontrava mais inquieta, pois trabalharia com estudantes adolescentes, pessoas com quase a mesma idade ${ }^{2}$ que eu, quando não mais velhas. A responsabilidade por estar à frente de uma turma com esta característica já me deixava "atormentada" em certos instantes.

Apesar de todos os comentários felizes dos demais colegas que já tinham cumprido essa etapa da graduação, eu ainda me sentia insegura. Adolescentes, a melhor fase da vida de

\footnotetext{
${ }^{1}$ Leia-se por imprevistos situações não condizentes com a Lei de Diretrizes e Bases da Educação (LDB) presenciadas pela licencianda durante seu primeiro estágio.

${ }^{2} \mathrm{Na}$ referida época a autora estava com vinte e um anos de idade. ISSN 2526-2882 
uma pessoa e eu ali, com a responsabilidade de uma turma, ensinando a disciplina pouco apreciada ${ }^{3}$ por muitos alunos.

Por outro lado, o fato de que a turma que eu escolhera era no turno da noite - noturna - me deixava um tanto quanto mais aliviada. Pensava:

Bom, talvez eles sejam todos mais velhos que eu, daí é mais fácil, estarão ali na sala de aula para estudar mesmo! Bem, talvez devido a isso, eu tenha que ter um pouco mais de pulso e de maleabilidade, visto que todos já devem trabalhar e chegarão nas aulas cansados e dispersos. - Ainda por esse lado, o relacionamento e as conversas fluiriam melhor. Bem, eles têm quase a minha idade, isso vai facilitar meu entrosamento! (Autora, 2015).

Foi com estas expectativas que cheguei na sala de aula, mesmo após ter saído desencantada de meu primeiro estágio. Estava confiante que tudo daria certo nesse segundo estágio. Outra escola, novos alunos, novas caras, novos sonhos. Tudo que um professor precisa para manter acesa a chama da esperança de dias melhores.

\section{A preparação para o estágio}

Naquela altura do campeonato, ou melhor, do curso de Licenciatura em Matemática, ficava me perguntando onde usaria todas as disciplinas de Física, Álgebras e Análise que tive que cursar, pois em meu primeiro estágio utilizei conhecimentos adquiridos basicamente nas disciplinas pedagógicas 4 e de alguns conceitos de Matemática Básica que apenas com um livro didático eu conseguiria explicar e ensinar.

Grande ilusão. Atualmente, depois de trabalhar com acompanhamento pedagógico de alunos, percebo o quão importante foram às disciplinas de Análise Real e todas as Álgebras. Claro, acredito que o modo como o professor do curso de licenciatura avança com estas disciplinas influencia totalmente no modo como o aluno percebe a conexão entre estes conhecimentos e a prática. Mas agora admito que o elas fundamentam e explicam conceitos que podem e deveriam serem aplicados nas aulas de matemática. Volto a outra questão que poucas vezes é tratada: porque o distanciamento entre a matemática escolar e a matemática dos matemáticos? Como poderia ser abordado esse elo entre a produção do cálculo, a divulgação desse conhecimento, presença dele nos currículos e a abordagem presente nos livros didáticos?

Essa questão se mostra fundamental para a compreensão dos modos e meios de produção dos conhecimentos e a importância deles nos currículos escolares. As vezes considero

\footnotetext{
${ }^{3}$ Matemática: Disciplina que por senso comum é vista como difícil e não prazerosa.

${ }^{4}$ Disciplinas pedagógicas: disciplinas de cunho pedagógico que estão presentes na grade curricular deste curso de licenciatura em matemática. À exemplo: Laboratórios de Ensino, Fundamentos Psicológicos da Educação, Trabalho de Campo. Para saber mais sobre a grade curricular do curso, acesse: 〈https://institucional.ufpel.edu.br/cursos/cod/3800>. ISSN 2526-2882 
que essa pode ser uma das razões que torna a disciplina de matemática, uma disciplina que não tem sentido para os estudantes. Pois os estudantes não percebem o vínculo do conhecimento matemático com o dia-a-dia.

Rodney Bassanezi (2002), tenta em suas pesquisas, aproximar essa matemática dos matemáticos da matemática escolar, publicando o livro Ensino-aprendizagem com Modelagem Matemática e, consagra um tema - por exemplo - que é a plantação de batatas 5 . Bassanezi retrata a importância do cálculo infinitesimal para que possamos calcular a produtividade de uma lavoura de produção de batatas. E, teríamos muitos outros exemplos para apresentar aqui, mas não é o foco dessa reflexão.

Mas meu interesse é retratar a importância da formação de professores trabalhar com a relação entre o conhecimento científico e o conhecimento escolar, tendo como referência os livros didáticos.

Mas voltando ao segundo estágio, percebi que da mesma forma que no primeiro, das disciplinas cursadas ao logo da graduação, fiz o uso de todas as práticas e teorias estudadas ao longo dos Laboratórios de Ensino ${ }^{6}$ e, para a aplicação do conteúdo utilizei - me dê uma parte muito pequena e inicial da cadeira de Pré-Cálculo7, realizada em meu primeiro semestre. Nessa minha “queixa”, cabe a minha inquietação que percebi logo no primeiro semestre.

Ao entrar para o Curso de Licenciatura em Matemática da UFPel em 2011, eu, Laura Leal Moreira, vinda de uma cidade pequena do interior do estado do Rio Grande do Sul, imaginei que logo nas primeiras aulas do meu curso de graduação, eu aprenderia a "fazer continhas" e a principalmente "ensinar continhas". Quando o primeiro dia de aula chegou, para minha desilusão vi uma vastidão de letras, Axiomas, Teoremas e meus números e as didáticas em nenhum lugar. (Autora, 2015)

Apesar de todo o desencanto inicial do curso, ainda sim me mantive firme e imaginei que seria útil a dominação de todos os teoremas e axiomas de algumas disciplinas, pois quem seria eu para julgar as disciplinas propostas em um curso de graduação. Levei comigo o pensamento de que eles (os teoremas, axiomas...), me dariam suporte em sala de aula no momento de minha atuação como professora de Matemática. Hoje, após o término do curso de mestrado e em busca de um programa de doutorado, após ter cumprido os estágios e trabalhado com o acompanhamento pedagógico, acredito sim que elas influenciam e podem serem utilizadas em sala de aula.

Mas, ainda cabe aqui o registro de uma outra indignação: Porque essa matemática tão abstrata é ensinada em um curso de Licenciatura em Matemática? Porque elas não são

\footnotetext{
${ }^{5}$ Disponível em:https://www.periodicos.unifra.br/index.php/disciplinarumNT/article/download/.../1170

${ }^{6}$ Laboratório de Ensino de Matemática (LEMA).

${ }^{7}$ Disciplina do primeiro semestre do curso de Licenciatura em Matemática (UFPel). ISSN 2526-2882 
ensinadas de forma mais prática, com exemplos de uma sala de aula do Ensino Fundamental e Médio? Isso já resolveria em parte a minha indignação. Agora, porque eu preciso aprender todas as três disciplinas de físicas básicas (nada básicas), as mesmas físicas ensinadas ao curso de Licenciatura em Física, se nem ao menos sairei com o grau de licenciada em física? Essas interrogações ainda persistem.

Obviamente comentários para rebater as minhas inquietações surgem durante conversas com meus colegas, evidenciando a necessidade de ser um curso completo para quem, também, deseja seguir em áreas como a da Matemática Pura ou Aplicada. Mas, a pergunta que fica é: e quem vai para a sala de aula, atuar como licenciada em Matemática em uma escola pública não precisa de mais cadeiras de práticas pedagógicas, didáticas e afins para tentar mudar o quadro da "cultura escolar" (JULIA, 2001) que toma conta das salas de aula? Considero que esse é mais um dos problemas nos cursos de licenciatura, ou seja, desenvolver nos futuros professores a capacidade crítica para romper com a cultura escolar vigente.

Nessa perspectiva, minha esperança recai em alguns professores do curso de Licenciatura em Matemática que se tornaram uma referência para minha formação. Verdadeiros mestres. Professores que independentemente da área que você decidiu seguir, continuam a te apoiar e a respeitar a sua decisão. No entanto, também, tive o desprazer de conviver com algumas pessoas.

Colegas que não aceitavam o fato de que estarem em um curso de Licenciatura em Matemática e, porque escolheram outros caminhos a trilhar, tornaram-se durante a formação “juízes de verdades”, julgando professores, colegas e demais pessoas que não concordassem com sua opinião. Pessoas de diálogo tendendo a zero. Não admitindo o diferente, o que preocupa, pois se não aceitam as diferenças durante o período de formação, como farão essa aceitação na prática profissional, como conviverão com seus futuros alunos?

Demorei um pouco a compreender o porquê de tantos colegas assim, será em função dos exemplos de alguns professores? Professores estes que não deveriam serem chamados de professor pois não fazem jus ao significado da palavra. Professores que lamentaram ver minha turma chegando ao final do curso, pois alegavam que "quem não consegue passar em pré cálculo nunca chegará em análise.” Professores estes, que tornaram alguns alunos seus discípulos, semeando arrogância e tornando a convivência conflituosa.

Hoje, depois de formada e um pouco mais ciente do mundo, com maturidade e conhecimento de outra instituição - onde fiz meu curso de mestrado - acredito que todo curso nos proporciona bons e maus exemplos, bastava a cada um tomar a sua decisão ao segui-los, ou não. 


\section{As experiências}

Estava feliz em meu primeiro dia de meu primeiro estágio. Ali estariam adolescentes que eu tanto temia e tanto queria poder compartilhar dessa experiência. Porém um problema lembrado minutos antes de começar a aula me deixou chateada: meus períodos de estágio seriam os últimos de uma terça-feira à noite e o último da quarta-feira. Quando comentei aos demais professores da escola sobre isso os mesmos me alertaram que eu nunca teria alunos em sala de aula.

Ao entrar em sala de aula pela primeira vez, os comentários dos professores se fizeram verdade. Dos trinta e quatro nomes de minha folha de chamada, em sala de aula tive doze alunos. Processo este que se repetiu durante todo o período de regimento da turma. Nunca tive mais que doze alunos presentes.

As aulas seguiriam, então. Tive aulas com quatros, três, dois e cheguei a passar dois períodos de aula com apenas um aluno. Ao questioná-los sobre este problema, não obtive muito sucesso nas respostas: Cansaço, perigo na volta para casa, ou simplesmente o não querer assistir a aula.

Em algumas outras aulas voltei a questionar sobre o assunto. Perguntei se eles não compareciam devido ao cansaço do trabalho e levei meu exemplo de quando cursava o Ensino Médio, pois sabia que não era fácil, mas argumentei que depois recompensaria. Para minha surpresa dois alunos me relataram que trabalhavam. Os demais afirmaram que não iam para aula porque não "queriam".

Este problema da frequência me levou a ter que agir de forma diferente em sala de aula, pois não poderia iniciar um conteúdo novo ou realizar alguma atividade avaliativa com a minoria da turma presente. Este processo fez com que a cada nova aula, eu retomasse o conteúdo anterior, tirasse todas as dúvidas e prosseguisse o que me gerou um atraso significativo na gama de conteúdos programados daquele semestre. Mas tudo bem, isso fazia parte do planejado.

Contudo, apesar de todos os problemas relacionados à frequência superei minhas expectativas ao trabalhar com adolescentes. O entrosamento com a turma foi um ponto muito positivo, pois no momento que consegui a confiança dos mesmos, as dúvidas sobre os conteúdos começaram a surgir e eles não tiveram nem um pouco de constrangimento ao me falar sobre o que não haviam entendido. Enfim, ponto para eles e ponto para mim. Saía da sala de aula com a certeza de que tinha feito minha parte e que os alunos haviam aprendido.

No entanto, em virtude da pouca quantidade de alunos em sala de aula, minhas aulas não foram marcadas pela emoção ou acontecimentos de grande repercussão, porém quando se é professor, ou quando se está no papel de um professor, todo e qualquer acontecimento marca. 
No entanto, salientarei aqui dois momentos que me deixaram um pouco (des)iludida com a profissão que me esperavam, mas que foram entendidos como desafios.

Em meu segundo dia de estágio, como regente da turma entrei para a sala de aula e minha turma estava com um número considerável de alunos. Fiquei muito empolgada, pois parecia que o quadro da 'falta de alunos' seria algo esporádico. Escutei alguns cochichos entre os alunos do tipo questionando se eu era professora mesmo e alguns dizendo que "agora iriam frequentar as aulas".

Enfim, eu era a professora e apesar da imensa vontade de rir de nervosa da situação, engoli o medo e comentei com eles de que havia escutado e não tinha gostado dos comentários. O silêncio tomou conta da aula. Comecei então a realizar a chamada, olhando para cada aluno, assim que o mesmo respondesse. Para minha surpresa, quando fui conferir o número de alunos que estavam presentes na folha de chamada com os presentes em sala de aula, reparei em um número absurdo de pessoas presentes que não eram meus alunos.

Na hora só consegui rir e então resolvi entrar na brincadeira. Pedi a um dos alunos que sabia que não era de minha turma o caderno emprestado para "olhar onde eu havia parado com o conteúdo”. Foi aí que o mesmo se entregou dizendo que não era meu aluno e então eu pedi para que os discentes que não eram da referida turma que se retirassem para que eu pudesse conversar com a minha turma. Os alunos das outras turmas se retiraram e eu iniciei a conversa sobre o ocorrido. Depois de muitos comentários para desviar o assunto, alguns assumiram que "espalharam" para as outras turmas que a professora deles era "novinha e bonita"8 e os demais colegas da escola "precisavam ir conferir".

Nunca me imaginei passando por uma situação assim. Confesso que achei engraçado e até levei na brincadeira após ter saído da aula, porém a situação no momento me deixou muito envergonhada e constrangida. Refletindo sobre essa situação, hoje tenho noção de que não reagiria da mesma forma, o assédio que é assunto tão presente e tira tantas vidas de mulheres, não foi percebido por mim. Naquela época considerei uma brincadeira, mas atualmente tenho ciência do quanto poderia ter me afetado psicologicamente.

Assédio é assunto sério e deveria ter sido debatido por mim com os alunos, mas naqueles anos eu apenas ignorei. Eu entendo que é complicado entrar para a escola quebrando um padrão, como os próprios alunos mencionaram, visto que eles não tinham contato com professoras com idade semelhante à deles, mas havia uma relação docente entre aluno e professor que foi quebrada. Perante mim, mulher e professora.

O segundo momento marcante desse meu segundo estágio e que me deixou entristecida, em alguns momentos foi a constante busca de alunos nos corredores e/ou pátio

${ }^{8}$ Novinha: termo usado atualmente para se referir a uma pessoa com aparência de jovem. ISSN 2526-2882

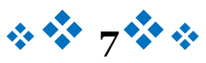


da escola, visto que já havia começado a aula e eles não "queriam subir" para assistir as aulas. Não entendia como uma aula, o local onde se pode aprender muito pode ser tão entediante para alguém. Fiquei inúmera vezes entristecida com isso e achava inadmissíveis aqueles comportamentos.

Outra reflexão que faço e hoje consigo entender melhor, refere-se a falta de encantamento por aprender destes alunos. Eu acredito que diante de um mundo tão globalizado e tão cheio de novas descobertas, e a escola com seu modelo tradicional não consegue competir com o mundo fora dos portões. A internet facilitou e adentrou a vida dos alunos com informações a um clique e isso dificultou o trabalho da instituição escolar. É decepcionante admitir que ainda precisamos mudar muito para conseguir fazer com que o jovem e o adolescente voltem a pensar a educação como algo que lhes é útil e que a escola pode ser maior do que a transmissão de conhecimentos.

Essa reflexão me levou aos estudos de Bernard Charlot (2001) sobre a relação com o saber. As pesquisas realizadas por esse autor e sua equipe sobre a relação com o saber nas escolas de periferia na França indicaram-me um caminho para tentar compreender, pelo menos em parte, o problema observado com os meus alunos. Penso que precisamos analisar, de forma mais abrangente, a relação dos estudantes com o saber - o que é ensinado nas escolas - e com a própria instituição. Por exemplo em Charlot (2000), o autor sugere que o problema do insucesso dos alunos em matemática, pode ser um dos reflexos da relação com essa instituição que são "obrigados” a frequentar.

\section{Percepção da Aprendizagem dos alunos}

Como já mencionado em outro momento deste texto, não obtive dias com "volume considerável" de alunos. Eu assumia os períodos e encontrava os alunos que não estavam dispostos a ficar para minha aula, no corredor indo embora sem cerimônia. No entanto esse problema me deixava triste e intrigada pois não entendia como eles simplesmente iam embora da escola, uma vez que havia uma portaria para identificação de acesso e saída da mesma.

Até que em determinada aula retornei ao assunto da frequência e das saídas das aulas, porém desta vez perguntando aos alunos presentes qual deles já tinham maioridade, porque talvez isso me ajudasse a entender como eles obtinham autorização para ir embora. Para minha surpresa e decepção, apenas três alunos eram "maior de idade”. Questionei-os perguntando sobre a portaria, o que os menores faziam para sair da escola, visto que em outras escolas que tive contato, apenas alunos com idade maior ou igual a dezoito anos tinham esse acesso livre. A resposta deles me desestimulou ainda mais: não havia controle algum. Todo e qualquer aluno podia entrar e sair a hora como bem entendesse. 
Diante disto, fui conversar com os outros professores. Eles tornaram a me dizer que realmente este era um problema grande do "noturno". Os mesmos ainda me alertaram dizendo que nada seria feito, visto que a portaria era uma "desordem" e que não haveria uma mudança, pois, a escola estava repleta de alunos violentos, o que poderia gerar uma revolta com ataques a escola. Contrariada, aceitei este fato e decidi que teria que arranjar alguma forma de lidar com isso em minhas aulas.

Desse modo, toda a aula funcionava da mesma maneira: eu entrava para a sala de aula, observava quantos alunos restavam, olhava os cadernos dos mesmos para poder ter uma ideia de qual conteúdo deveria retomar e começava minha aula. Foi este o processo durante todo o período que fiquei com essa turma. Apesar de ter que retomar o conteúdo toda aula, ou muitas vezes retomar duas ou três aulas anteriores, essa prática ajudou muito no aprendizado dos alunos pois a cada vez que eu retomava o conteúdo, os alunos que estavam presentes em duas aulas consecutivas já sabiam a matéria e acabavam ajudando os demais colegas que ainda tinham dúvidas.

Considerava que toda essa retomada de conteúdo, os ajudaria na hora de uma avaliação, pois já havia optado por não realizar nenhuma prova com consulta ao material devido a pedido de alguns alunos. Avisei sobre a data da prova, pedi para que os mesmos estudassem, relessem a matéria porque não faria uma prova com nada diferente do que eles haviam visto em sala de aula. Ao corrigir a avaliação, para minha decepção nem mesmo os alunos que pediram para que a prova fosse sem consulta ao material, tiveram bons resultados.

Este momento é angustiante para um professor. Olhar para uma prova, baseada nas listas de exercícios que foram feitos e refeitos em aula e nem mesmo quem parecia que estava aprendendo obteve um bom resultado, essa situação me deixou frustrada. Ao retornar à sala de aula, perguntei o que havia acontecido, retomei algumas questões e notei que eles sabiam o conteúdo. Alguns, também, me falaram que "não tinham tido vontade de estudar para a prova".

Percebi então que o problema dos maus resultados poderia ter vindo de muitos fatores: o fato deles não retomarem a matéria, do nervosismo e de minha escolha do método de avaliação e outros aspectos tratados por Charlot (2001). Compreendi que uma prova pode não ser uma boa avaliação. O termo "prova" soa pesado e faz com que o aluno, mesmo sabendo o conteúdo, responda as questões de forma equivocada por nervosismo. A partir desse momento decidi que avaliaria os alunos pelas aulas e não mais por "provas".

Assim considerei que o problema da avaliação eu havia resolvido, no entanto o "não ter vontade de estudar" eu não conseguia entender. Eu, Laura, não conseguia entender como os alunos estando em um local repleto de conhecimento e podendo aprender muito, não tinham essa vontade. Comparava erroneamente com a minha época e a minha cidade natal. 
Sim erroneamente porque aqueles alunos estavam vivendo outra realidade, a realidade deles e não a minha de quatro anos atrás. O mundo já tinha mudado muito desde então e eu, não havia percebido. Como falei anteriormente, hoje eu entendo a falta de prazer que a sala de aula oferece, diante da tecnologia na "ponta dos dedos" mas naquela época eu ficava completamente incrédula com essa situação.

\section{Percepção da minha Aprendizagem}

Nesse momento de refletir sobre o meu aprendizado, nunca consigo pensar em outra frase a não ser a de meu pai, a qual escutei/escuto muitas vezes. Acredito que todo tipo de experiência, seja ela boa ou tuim, nos trará alguma reflexão positiva. Ele dizia/diz: "Na vida, o que se leva é o conhecimento que tu adquires. Esse ninguém te tira".

Os estágios curriculares trouxeram-me inúmeras experiências boas. A melhor coisa do mundo é ouvir um aluno dizendo que, com você ele aprendeu algo ou então, que professor não fica feliz ao encontrar um ex-aluno na rua e, ainda assim dizer: oi Professora! Em nossa graduação, o estágio é uma parcela pequena de tudo que virá após a formatura. Todos os problemas que surgiram no estágio, acontecerão de novo e de novo e de novo. Cabe a cada um decidir a melhor forma de lidar com eles e não deixar se abalar por estas dificuldades.

Por muito tempo carreguei comigo o sonho e a vontade de ser professora. A emoção de conseguir transferir o que se sabe e aprender sempre mais é muito gratificante nos engrandece. Saí de meu primeiro estágio tendo a certeza de que queria ser professora, de que nada me faria mais feliz. Na época que terminei o Estágio II, levava comigo esse desejo um pouco apagado.

Não acreditava que estava preparada para lecionar em uma escola pública com a mesma realidade enfrentada nesse meu segundo estágio. Sabia que ainda me sobravam inúmeras oportunidades, como as escolas particulares, ou quem sabe uma escola de um município menor, ou talvez os cursinhos pré-vestibulares. No entanto eu queria ser professora para poder ajudar a quem precisa.

Não que um aluno de uma escola particular ou um aluno de cursinho não precise de ajuda, claro que sim, eles também precisam. Mas gostaria de ajudar a quem precisa no real sentido da palavra. Ajudar a quem vive em uma realidade um pouco menos privilegiada socialmente. Ajudar quem mesmo diante das inúmeras dificuldades ainda tem a vontade de aprender e quer lutar por isso.

Contudo, diante da realidade vivenciada e de outros exemplos, não sabia se ainda restava esperanças em lugares como os que eu descrevi. Então parti para a realização do curso de mestrado. Hoje já tenho o desejo da sala de aula, mas mais fortemente, o desejo da sala de aula da formação do professor. Admiro ainda mais quem acredita na Licenciatura e sai da ISSN 2526-2882

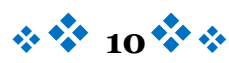


graduação direto para a sala de aula. Querer enfrentar com todos os problemas que acontecem é de uma coragem imensa. Só tenho a agradecer as pessoas que optam por isso. Sem essas pessoas destemidas o mundo viraria um abismo.

De todas as vivências que ocorreram em meus estágios, não gostaria de seguir enfatizando as que considerei difíceis, visto que é muito fácil julgar o que está errado sem considerar o contexto. No entanto me resta, ainda, dizer que estes estágios me ajudaram a moldar as minhas escolhas, e que foi de extrema importância para delinear os próximos passos de minha vida.

\section{Fechou-se mais um ciclo...}

Nossa vida é repleta de ciclos. Ciclos matemáticos são compostos pelo número dez. O ciclo das horas é marcado pelo número 60. 60 minutos! O ciclo de um dia, marcado pelas 24horas. Horas, horas que muitas vezes nesse semestre de estágio foram poucas devido a tanta carga horária e coisas a se fazer.

Por fim, encerrei mais um ciclo com esse relato. Um ciclo que iniciou lá em meu primeiro estágio, sob momentos de agonia e medo ao enfrentar uma turma. Um ciclo que se encerra, cheio de decisões tomadas. Decisões que não foram fáceis. Entreguei esse relato com a certeza de que não desejava lecionar matemática, em uma escola nas condições que tinha vivenciado naquele estágio.

Escolhi ser professora para compartilhar saber. Era um tanto covarde, mas tinha medo de ingressar como professora de uma escola pública e deixar o lugar tomar conta de mim. Não queria fazer parte de uma escola que é marcada pela aprovação de alunos a todo custo, pela subestimação da capacidade dos alunos, pela sala de aula mesmo cheia de pessoas, vazia de sede por conhecimento.

Ao avaliar-me dentro da sala de aula, como regente de uma turma, posso dizer que dei o meu melhor. O meu melhor aqui, não significa que "fiz muitas avaliações que não exigiam dos alunos", "fiz todas as provas em duplas porque os alunos não passariam se fosse uma prova sem consulta”. Não, fiz o meu melhor no que eu acredito que seja melhor. Fui professora e nunca me neguei a uma explicação. Expliquei inúmeras vezes os mesmos conteúdos e se fosse preciso explicaria novamente. Meus alunos tinham e tem o direito de aprender. Aprendi muito com eles.

Em relação ao avaliar-me sobre o trabalho que regi na turma, não sou capaz de responder a esta questão. Não acho que uma prova, ou um trabalho dirá que o que eu fiz foi uma boa atuação, pois não acredito que uma prova seja uma boa avaliação para nada. Logo sobre este tópico não descreverei nada a mais, uma vez que prefiro acreditar que o que fiz de 
bom, os alunos levarão consigo e quanto a mim, não preciso de provas para me comprovar quanto aos meus próprios esforços.

\section{E de tudo isso, o que levo comigo?}

O Estágio foi uma das etapas mais importantes da minha graduação. Conhecer a realidade escolar e poder participar de uma troca de saberes tão rica é muito gratificante.

Como já mencionei, foi nesse meu segundo estágio que decidi o rumo que queria tomar ao licenciar-me. Não é uma resposta muito motivadora, mas com certeza era o que eu estava sentindo. Eu não podia aceitar lecionar não me sentido preparada para tudo que iria enfrentar.

Sei que todos os momentos foram enriquecedores. E é de extrema valia tudo que vivi. Por isso mesmo é que decidi não atuar logo em seguida do término do curso, pois ser um professor é bem mais ser o mediador do conhecimento. É ser amigo, irmão, conselheiro. É ir pra casa com sorriso de "orelha a orelha” por ter tirado a dúvida de alguém. É perceber nos olhos dos alunos o quão interessante ou não sua aula está.

Infelizmente depois de tudo que presenciei em meus dois estágios, não sabia se conseguiria ser esse professor que descrevi. Diante disto, preferi me fechar, esperar por novas experiências e quem sabe logo mais voltar para a sala de aula.

$\mathrm{E}$, foi exatamente esse o rumo que tomei após terminar a licenciatura. Decidi ingressar num programa de mestrado e estudar mais. Foram dois anos intensos de muitas novidades e reflexões. Hoje, escrevendo esse texto já não compactuo com o pensamento da Laura de três anos atrás. Durante o período pós licenciatura, tive a oportunidade de atuar como professora e entendi que não é porque "tudo está errado" que eu preciso seguir essa linha. E, que acomodar-se é uma questão de escolha.

Por fim esse relato procurou apresentar os (des)encantamentos e desafios de uma aluna de um curso de licenciatura em Matemática da Universidade Federal de Pelotas, durante a realização de seus estágios. Esse relato, hoje me fez refletir ainda mais sobre tudo que fora vivenciado por mim e como eu enxergo, atualmente, os "monstros" que me assombravam com mais clareza e um pingo de riso por tanta ingenuidade. Conforme Jenkins (2013) fala, [...] nenhuma leitura, ainda que efetuada pela mesma pessoa, é passível de produzir os mesmos efeitos repetidamente. Isso quer dizer que os autores não têm como impingir suas intenções/interpretações ao leitor, afirmação se comprova na prática com essa releitura de meu passado. 


\section{Referências}

BASSANEZI, R. C. Ensino-aprendizagem com Modelagem Matemática. São Paulo: Contexto, 2002.

CHARLOT, B. Da Relação com o Saber :Elementos para uma teoria. Artmed,200o. (org) Os Jovens e o Saber: Perspectivas mundiais. Trad. Fátima Murad. Porto Alegre: Artmed, 2001. Formação de Professores: a pesquisa e a política educacional. In: Professor Reflexivo no Brasil: gênese e crítica de um conceito. São Paulo:Cortez,2002 JENKINS, K. A História Repensada. Tradução de Mario Vilela. Revisão Técnica de Margareth Rago. 4ed. São Paulo. Editora Contexto, 2013.120p.

JULIA, D. A Cultura Escolar como Objeto Histórico. Este texto é tradução do artigo de Julia: "La culture scolaire comme objet historique", Paedagogica Historica. International journal of the history of education (Suppl. Series, vol. I, coord.

NOVOA. A.; DEPAEPE, M.; e JOHANNINGMEIER, E.V. 1995, pp. 353-382). Publicado na Revista brasileira de história da educação $\mathrm{n}^{\circ} 1$ jan./jun. 2001. Disponível em: periodicos.uem.br/ojs/index.php/rbhe/article/view/38749

SOARES, M. Metamemória-memórias: travessia de uma educadoraSão Paulo: Cortez, 2001.

\section{Biografia Resumida}

Laura Leal Moreira: Licenciada em Matemática pela UFPEL; Mestra em Educação em Ciências e em Matemática pela UFPR; Membra do Grupo de História Oral e Educação Matemática (GHOEM).

Link do lattes: http://lattes.cnpq.br/5979473277948539

e-mail: lauraamoreira@gmail.com

Denise Nascimento Silveira: Graduação em Matemática pela UCPEL; Mestra em Educação pela UFPEL; Doutora em Educação pela UNISOS; Professora Adjunta da Universidade Federal de Pelotas; Líder na UFPEL do grupo de pesquisa Formação de Professores de Matemática, vínculo com os Programa de Pós-graduação em Educação Matemática (Mestrado Acadêmico), Programa de Pós-graduação em Ensino 
de Ciências e Matemática e Programa de Pós-graduação em Educação e Tecnologia (Mestrados Profissionais).

Link do lattes: http://lattes.cnpq.br/4866864802999230

e-mail: silveiradenise13@gmail.com 